\title{
Análise da arborização urbana de três cidades da região norte do Estado de Mato Grosso
}

\author{
Danielucia Noya ALMEIDA ${ }^{1}$, Rubens Marques RONDON NETO²
}

\begin{abstract}
RESUMO
O presente estudo teve por objetivo analisar a arborização viária de três cidades da regiáo norte do Estado de Mato Grosso, sendo: Alta Floresta, Carlinda e Nova Monte Verde. Foi levantado um total de 663 indivíduos, distribuídos em 20 famílias botânicas, 30 gêneros e 31 espécies. 51,6\% das espécies são exóticas à flora brasileira e 48,4\% são nativas. As espécies mais frequentes nas cidades avaliadas foram: Licania tomentosa (45,4\%), Ficus benjamina (18,1\%) e Roystonea oleraceae (13,6\%). Nas três cidades, mais de $80 \%$ da população obteve diâmetro â altura do solo inferior a $0,4 \mathrm{~m}$ e mais de $60 \%$ da população estava abaixo de 6,0 $\mathrm{m}$ de altura total, em todas as cidades. Os indivíduos plantados sob a fiação elétrica representaram menos de $50 \%$ da população amostrada, nas três cidades amostradas, e altura média das árvores, sob a fiação, variou de 3,2 m (Nova Monte Verde) a 5,9 m (Alta Floresta). Mais de 85\% dos indivíduos apresentaram bifurcação abaixo de 1,80 m. A densidade de árvores $/ \mathrm{km}$ de calçada estimado nas cidades avaliadas variou entre 47,7 árvores $/ \mathrm{km}$ (Alta Floresta) e 56,0 árvores/km (Carlinda). O índice de diversidade de Shannon estimado foi 1,17 (Carlinda), 1,75 (Nova Monte Verde) e 1,76 (Alta Floresta). A largura das vias e recuos permite o plantio de espécies de médio e grande porte. Contudo, é essencial o planejamento da arborização urbana e definição de critérios e técnicas adequadas para a realização de plantios e manutençóes.
\end{abstract}

PALAVRAS-CHAVE: arborização viária, Alta Floresta, Carlinda, Nova Monte Verde.

\section{Urban forestry analysis in three cities of northern Mato Grosso}

\section{ABSTRACT}

The objective of the present study was to analyze roadside forestry in three cities in the northern region in the State of Mato Grosso. The cities evaluated were Alta Floresta, Carlinda and Nova Monte Verde. We made a survey of 663 individuals, distributed in 20 botanical families, 30 genera and 31 species. Over 51.6\% of this species are exotic to the Brazilian flora and $48.4 \%$ native. The species most frequent in the evaluated cities had been: Licania tomentosa (45.4\%), Ficus benjamina (18.1\%) and Roystonea oleraceae (13.6\%). In the three cities, more than $80 \%$ of the population had got diameter at the height of the ground inferior to $0.4 \mathrm{~m}$ and more than $60 \%$ of the population had lass than of $6.0 \mathrm{~m}$ de total height, in all the cities. The individuals under the electric wiring represent fewer than $50 \%$ of the population, in the two sampled cities, and average height of the trees, under the wiring was of $3.2 \mathrm{~m}$ (Nova Monte Verde) and $5.9 \mathrm{~m}$ (Alta Floresta). More than $85 \%$ of the individuals had presented bifurcation below of $1.8 \mathrm{~m}$. The density of trees $/ \mathrm{km}$ of sidewalk estimate in the evaluated cities varied between 47.7 trees $/ \mathrm{km}$ (Alta Floresta) and 56.0 trees $/ \mathrm{km}$ (Carlinda). The Shannon diversity index estimate was 1.17 (Carlinda), 1.75 (Nova Monte Verde ) and 1.76 (Alta Floresta). The width of the streets and showed recesses allows the planting of species of medium to larger size. However, it is essential for the planning of urban forestry, definition of criteria and techniques appropriate to the accomplishment of planting and maintenance.

KEYWORDS: roadside reforestation, Alta Floresta, Carlinda, Nova Monte Verde.

1 Universidade Federal de Mato Grosso, E-mail: noyadani@yahoo.com.br

${ }^{2}$ Universidade do Estado de Mato Grosso, E-mail: rubensrondon@yahoo.com.br 


\section{INTRODUÇÃO}

O efeito da urbanizaçáo acelerada tem provocado grandes modificaçóes sobre a paisagem (GONÇALVES e PAIVA, 2004). Nesse contexto, a arborizaçáo urbana é um quesito importante para proporcionar melhorias significativas na qualidade de vida da população, sob diversos aspectos (MILANO e DALCIN, 2000). Devido a sua elevada relevância, a arborização urbana vem se destacando nas discussôes sobre os problemas das cidades, na busca de maior qualidade de vida para a populaçáo (WESTPHAL, 2003).

Embora as árvores possam ser encontradas em vários ambientes urbanos, a rua é o local tradicional da arborização urbana, onde as árvores são plantadas enfileiradas nas calçadas (GONÇALVES e PAIVA, 2004), geralmente, dispensando planejamento prévio e manutenção adequada (RACHID e COUTO, 1999) e legislação específica escassa.

A falta de planejamento na implantação e na manutenção da arborização urbana é evidenciada em diversas cidades brasileiras e mesmo em outros países, ocasionando problemas tais como: diversidade reduzida de espécies (McPHERSON, 2003; SILVA et al, 2007; MELO et al., 2007), uso excessivo de espécies exóticas (BIONDI e MACEDO, 2008) e manutenção deficiente (RACHID e COUTO, 1999; SILVA FILHO et al., 2002), o que acarreta conflitos entre as árvores e os elementos urbanos (VELASCO et al., 2006). No estado de Mato Grosso é facilmente possível constatar essa realidade (MARQUES, 2008).

Diante do cenário exposto, o presente trabalho teve como objetivo analisar a situação atual da arborização urbana em três cidades da região norte do Estado de Mato Grosso, a fim de obter subsídios que possam servir de base na discussão e elaboração do plano diretor da arborizaçáo urbana.

\section{METODOLOGIA}

O estudo foi realizado nas cidades de Alta Floresta, Carlinda e Nova Monte Verde, localizadas na regiáo do extremo norte do Estado de Mato Grosso. Com 54 municípios, o Norte mato-grossense compreende a maior mesoregiáo de Mato Grosso em números de municípios e em extensão territorial. A área ocupada por essa regiáo abrange cerca de $484.046 \mathrm{~km}^{2}$, ou seja, $53,6 \%$ da área total do Estado, o que é de $903.358 \mathrm{~km}^{2}$ (MATO GROSSO, 2005). A Tabela 1 apresenta informaçóes referentes aos aspectos geográficos e políticos dos três municípios estudados.

Pela classificação de Köppen a regiáo norte do Estado de Mato Grosso apresenta clima tipo Awi e temperatura média anual em torno de $25,4^{\circ} \mathrm{C}$, com uma precipitação média anual em torno de $2.200 \mathrm{~mm}$ (MATO GROSSO, 2008).

Os dados foram coletados através de amostragem aleatória simples, e anotados em uma ficha de campo previamente
Tabela 1 - Dados geográficos e políticos dos municípios de Alta Floresta, Carlinda e Nova Monte Verde, situados na região norte do Estado de Mato Grosso utilizados para análise da arborização urbana.

\begin{tabular}{|c|c|c|c|c|c|}
\hline \multirow{2}{*}{ Município } & \multirow{2}{*}{$\begin{array}{l}\text { Ano de } \\
\text { criaçãa } 0^{1}\end{array}$} & \multirow{2}{*}{$\begin{array}{c}\text { Área } \\
\text { geográfica } \\
\left(\mathrm{km}^{2}\right)^{1}\end{array}$} & \multirow{2}{*}{$\begin{array}{c}\text { Área } \\
\text { urbana } \\
\left(\mathrm{km}^{2}\right)^{2}\end{array}$} & \multicolumn{2}{|c|}{$N^{0}$. de habitantes ${ }^{1}$} \\
\hline & & & & Urbana & Rural \\
\hline Alta Floresta & 1979 & $8.974,70$ & 18,20 & 37.287 & 9.695 \\
\hline Carlinda & 1994 & $2.417,21$ & 3,39 & 3.074 & 9.222 \\
\hline Nova Monte Verde & 1991 & $6.500,17$ & 1,68 & 2.197 & 4.630 \\
\hline
\end{tabular}

Fonte: (1) MATO GROSSO (2008); (2) MATO GROSSO (2000)

preparada. Os levantamentos foram realizados no primeiro semestre do ano de 2008. As informaçôes coletadas consideraram os seguintes aspectos: localização e identificação da espécie, altura total e altura da bifurcação mensuradas com régua graduada, circunferência a $50 \mathrm{~cm}$ de altura do solo (CAS) mensurada com fita métrica, diâmetro da copa (sentidos N-S e E-W), distância entre as árvores e proximidade das infraestruturas urbanas, medidos com trena.

Para caracterizar o ambiente envolvido na arborização urbana foram procedidas as seguintes mediçôes: largura e comprimento da via, largura da calçada, largura do recuo (meio-fio até o muro), distância dos postes ao meio-fio, altura da fiação telefônica, altura da fiação de alta e baixa tensão.

A freqüência relativa de cada espécie foi calculada pela razão entre o número de indivíduos da espécie e o número total de espécimes, multiplicada por 100. As espécies amostradas foram classificadas quanto a origem, mediante consultas bibliográficas, tais como: Lorenzi (2002), Carvalho (2003), Lorenzi et al. (2003), Carvalho (2006) e Carvalho (2008). As espécies foram classificadas, também, quanto à aptidáo para a alimentação humana, baseada nas pesquisas bibliográficas citadas anteriormente e Shanley (2005) e Lorenzi et al. (2006). Os indivíduos inventariados foram classificados quanto ao de acordo com Mascaró e Mascaró (2005). Foi estimado o Índice de Diversidade de Shannon.

\section{RESULTADOS E DISCUSSÃO}

\section{Composição florística da arborização viária}

O percurso realizado nas três cidades avaliadas totalizou $13.210 \mathrm{~m}$ percorridos e possibilitou coletar dados da arborização em 17 redes viárias públicas asfaltadas, sendo: cinco vias em Carlinda ( $2.150 \mathrm{~m})$, seis vias em Nova Monte Verde $(4.310 \mathrm{~m})$ e quinze vias em Alta Floresta $(6.750 \mathrm{~m})$. No percurso foram levantados 663 indivíduos, pertencentes à 31 diferentes espécies.

Foram identificadas 08 espécies arbustivo-arbóreas sendo utilizadas na arborização urbana da cidade de Carlinda. Foram amostradas 19 espécies, tanto em Alta Floresta quanto em Nova Monte Verde. As famílias botânicas com maior 
número de espécies nas cidades avaliadas foram: Myrtaceae (4), Anacardiaceae (3) e Mimosaceae (3), no entanto, mesmo com uma única espécie, Chrysobalanaceae foi a família mais representativa, já que apresentou $45,4 \%$ dos indivíduos amostrados (Tabela 2). O número de espécies arbóreas encontradas nas três cidades estudadas pode ser considerado baixo em relação à outros estudos já realizados, como: Santos/ SP - 65 espécies (MENEGHETTI, 2003), Águas de São Pedro/SP - 161 espécies (BORTOLETO et al., 2007) e Curitiba/PR - 370 espécies (BIONDI e MACEDO, 2008).
Milano (1984) recomenda que cada espécie não deve ultrapassar $15 \%$ do total de indivíduos da populaçáo arbórea, considerando riscos de pragas e doenças, podendo comprometer a longevidade das espécies. Licania tomentosa apresentou frequência relativa acima desse limite nas três cidades estudadas, em Alta Floresta e Carlinda, Ficus benjamina também superou o limite recomendado e em Nova Monte Verde, Roystonea oleracea também se manteve acima desse limite. Por outro lado, foi constatado elevado número de espécies com baixa freqüência. Em Carlinda cinco espécies

Tabela 2 - Distribuição quantitativa das espécies encontradas na arborização viária das cidades de Nova Monte Verde, Alta Floresta e Carlinda, situadas na região norte do Estado de Mato Grosso, com os seus respectivos nomes científicos e comuns, quantidade de indivíduos amostrados (n), freqüência relativa em \% (FR) e origem ( $N$ = nativa e $E$ = exótica).

\begin{tabular}{|c|c|c|c|c|c|c|c|c|}
\hline \multirow{3}{*}{ Família/Nome científico } & \multirow{3}{*}{ Nome comum } & \multicolumn{6}{|c|}{ Cidade } & \multirow{3}{*}{ Origem } \\
\hline & & \multicolumn{2}{|c|}{ N. Monte Verde } & \multicolumn{2}{|c|}{ Alta Floresta } & \multicolumn{2}{|c|}{ Carlinda } & \\
\hline & & $\mathrm{n}$ & $\mathrm{FR}$ & $\mathrm{n}$ & FR & $\mathrm{n}$ & FR & \\
\hline $\begin{array}{l}\text { Anacardiaceae } \\
\text { Anacardium occidentale L. }\end{array}$ & Cajueiro & 1 & 0,42 & - & - & - & - & $\mathrm{N}$ \\
\hline $\begin{array}{l}\text { Anacardiaceae } \\
\text { Astronium fraxinifolium Schott \& Spreng. }\end{array}$ & Aroeira & - & - & - & - & 1 & 0,98 & $\mathrm{~N}$ \\
\hline $\begin{array}{l}\text { Anacardiaceae } \\
\text { Mangifera indica L. }\end{array}$ & Mangueira & 14 & 5,86 & 2 & 0,62 & - & - & $E$ \\
\hline $\begin{array}{l}\text { Pinaceae } \\
\text { Pinus sp }\end{array}$ & Pinheiro & - & - & 4 & 1,24 & 1 & 0,98 & $E$ \\
\hline $\begin{array}{l}\text { Arecaceae } \\
\text { Caryota urens L. }\end{array}$ & $\begin{array}{l}\text { Palmeira rabo } \\
\text { de peixe }\end{array}$ & 6 & 2,51 & - & - & - & - & $E$ \\
\hline $\begin{array}{l}\text { Arecaceae } \\
\text { Roystonea oleracea }\end{array}$ & $\begin{array}{l}\text { Palmeira } \\
\text { imperial }\end{array}$ & 65 & 27,20 & 12 & 3,73 & 13 & 12,75 & $E$ \\
\hline $\begin{array}{l}\text { Bignoniaceae } \\
\text { Tabebuia heptaphylla (Mart.) Standl }\end{array}$ & Ipê roxo & - & - & 2 & 0,62 & 1 & 0,98 & $\mathrm{~N}$ \\
\hline $\begin{array}{l}\text { Bombacaceae } \\
\text { Ceiba petandra (L.) Gaertn }\end{array}$ & Sumauma & - & - & 1 & 0,31 & - & - & $\mathrm{N}$ \\
\hline $\begin{array}{l}\text { Bombacaceae } \\
\text { Pachira aquatica Aubl. }\end{array}$ & Munguba & 2 & 0,84 & 26 & 8,07 & - & - & $\mathrm{N}$ \\
\hline $\begin{array}{l}\text { Caesalpinaceae } \\
\text { Caesalpinia peltophoroides DC }\end{array}$ & Sibipiruna & 7 & 2,93 & 33 & 10,25 & - & - & $\mathrm{N}$ \\
\hline $\begin{array}{l}\text { Chrysobalanaceae } \\
\text { Licania tomentosa (Benth.) Fritsch. }\end{array}$ & Oiti & 105 & 43,93 & 140 & 43,48 & 56 & 54,90 & $\mathrm{~N}$ \\
\hline $\begin{array}{l}\text { Combretaceae } \\
\text { Terminalia catappa L. }\end{array}$ & Sete copas & 2 & 0,84 & 2 & 0,62 & - & - & $E$ \\
\hline $\begin{array}{l}\text { Cupressaceae } \\
\text { Cupressus sp. }\end{array}$ & Cipreste & 6 & 2,51 & - & - & - & - & $E$ \\
\hline $\begin{array}{l}\text { Euphorbiaceae } \\
\text { Hevea brasiliensis }\end{array}$ & Seringueira & - & - & - & - & 1 & 0,98 & $\mathrm{~N}$ \\
\hline $\begin{array}{l}\text { Lauraceae } \\
\text { Persea americana }\end{array}$ & Abacate & - & - & 3 & 0,93 & - & - & $E$ \\
\hline $\begin{array}{l}\text { Lythraceae } \\
\text { Lagerstroemia indica L. }\end{array}$ & Extremosa & 9 & 3,77 & - & - & - & - & $E$ \\
\hline $\begin{array}{l}\text { Malvaceae } \\
\text { Theobroma cacao L. }\end{array}$ & Cacau & - & - & 1 & 0,31 & - & - & $\mathrm{N}$ \\
\hline
\end{tabular}




\begin{tabular}{|c|c|c|c|c|c|c|c|c|}
\hline \multirow{3}{*}{ Família/Nome científico } & \multirow{3}{*}{ Nome comum } & \multicolumn{6}{|c|}{ Cidade } & \multirow{3}{*}{ Origem } \\
\hline & & \multicolumn{2}{|c|}{ N. Monte Verde } & \multicolumn{2}{|c|}{ Alta Floresta } & \multicolumn{2}{|c|}{ Carlinda } & \\
\hline & & $\mathrm{n}$ & FR & $\mathrm{n}$ & FR & $\mathrm{n}$ & FR & \\
\hline $\begin{array}{l}\text { Meliaceae } \\
\text { Azadirachta indica A. Juss. }\end{array}$ & $\mathrm{Nim}$ & 1 & 0,42 & - & - & - & - & $E$ \\
\hline $\begin{array}{l}\text { Meliaceae } \\
\text { Cedrela fissilis Vell }\end{array}$ & Cedro & 1 & 0,42 & - & - & - & - & $\mathrm{N}$ \\
\hline $\begin{array}{l}\text { Mimosaceae } \\
\text { Acacia albida Del. }\end{array}$ & Acácia & - & - & 2 & 0,62 & 1 & 0,98 & $E$ \\
\hline $\begin{array}{l}\text { Mimosaceae } \\
\text { Inga edulis }\end{array}$ & Ingá & 1 & 0,42 & - & - & - & - & $\mathrm{N}$ \\
\hline $\begin{array}{l}\text { Moraceae } \\
\text { Artocarpus heterophyllus Lam. }\end{array}$ & Jaqueira & 1 & 0,42 & - & - & - & - & $E$ \\
\hline $\begin{array}{l}\text { Moraceae } \\
\text { Ficus benjamina }\end{array}$ & Ficus & 14 & 5,86 & 78 & 24,22 & 28 & 27,45 & $E$ \\
\hline $\begin{array}{l}\text { Myrtaceae } \\
\text { Eugenia uniflora L. }\end{array}$ & Pitanga & 1 & 0,42 & - & - & - & - & $\mathrm{N}$ \\
\hline $\begin{array}{l}\text { Myrtaceae } \\
\text { Psidium SP }\end{array}$ & Goiaba & 1 & 0,42 & 1 & 0,31 & - & - & $\mathrm{N}$ \\
\hline $\begin{array}{l}\text { Myrtaceae } \\
\text { Syzygim cumini }\end{array}$ & Jambolão & - & - & 2 & 0,62 & - & - & $E$ \\
\hline $\begin{array}{l}\text { Myrtaceae } \\
\text { Syzygium malaccense }\end{array}$ & $\begin{array}{l}\text { Jambo } \\
\text { vermelho }\end{array}$ & - & - & 8 & 2,48 & - & - & $E$ \\
\hline $\begin{array}{l}\text { Ramnaceae } \\
\text { Colubrina rufa }\end{array}$ & $\begin{array}{l}\text { Falso pau } \\
\text { brasil }\end{array}$ & - & - & 1 & 0,31 & - & - & $\mathrm{N}$ \\
\hline $\begin{array}{l}\text { Rubiaceae } \\
\text { Genipa americana L. }\end{array}$ & Jenipapo & 1 & 0,42 & - & - & - & - & $\mathrm{N}$ \\
\hline $\begin{array}{l}\text { Rutaceae } \\
\text { Citrus limonum }\end{array}$ & Limoeiro & 1 & 0,42 & - & - & - & - & $E$ \\
\hline $\begin{array}{l}\text { Rutaceae } \\
\text { Murraya paniculata (L.) Jacq. }\end{array}$ & Murta & - & - & 3 & 0,93 & - & - & $E$ \\
\hline TOTAL & 31 & 239 & 100 & 322 & 100 & 102 & 100 & \\
\hline
\end{tabular}

apresentaram freqüência abaixo de 1,0\%, em Nova Monte Verde e Alta Floresta, onze e doze espécies, respectivamente, apresentaram freqüência abaixo de 1,0\%.

A utilização de espécies exóticas à flora brasileira foi predominante em Nova Monte Verde (57,9\%) e Alta Floresta (52,6\%), já em Carlinda, as espécies nativas representaram $50 \%$ da população amostrada. A utilização de espécies nativas em áreas urbanas deve ser incentiva com o intuito de proteger e valorizar a flora local (SILVA FILHO e BORTOLETO, 2005). Entretanto, dentre as espécies nativas do Brasil, foi constatada baixa ocorrência de espécies naturais do bioma amazônico. Entre as espécies exóticas utilizadas em grandes proporçôes na arborização urbana das cidades estudadas, foi destacada a participação de Ficus benjamina. Santana e Santos (1999) comentam que as espécies do gênero Ficus causaram danificaçóes nas calçadas do Campus da Universidade Estadual de Feira de Santana, na cidade de Feira de Santana/BA.
Foram amostradas oito espécies frutíferas, em Nova Monte Verde e em Alta Floresta foram levantadas seis espécies adequadas à alimentação humana, porém, compreendendo poucos indivíduos e em algumas ocasióes apenas um indivíduo representou a espécie. Tal fato é caracterizado pela interferência da população local na arborização pela variedade de árvores frutíferas plantadas nas calçadas. Em Carlinda não ocorreu nenhuma espécie frutífera. Conforme Milano e Dalcin (2000) apesar das espécies frutíferas serem atrativas para a fauna, deve-se evitar o plantio dessas espécies em calçadas, pois esses frutos podem cair sobre a calçada, veículos ou pedestres que circulam no local, podendo servir, também, de alimento para vetores de doenças.

A ausência de legislação específica para atender ao planejamento urbano, nessas cidades, pode ter contribuído para essa distribuiçáo irregular das espécies. Dessa forma, a escolha das espécies para a arborização viária fica sob 
responsabilidade dos moradores, refletindo no plantio desordenado, sem a observância de critérios técnicos. Entretanto, Paiva e Gonçalves (2002) alertam que se o plantio aleatório das mudas é condenável, a participação comunitária na arborização urbana planejada, ao contrário, é uma prática recomendada como forma de educação ambiental.

Os valores obtidos para o índice de diversidade de Shannon (IDS) foram: Carlinda $(1,17)$, Nova Monte Verde $(1,75)$ e Alta Floresta $(1,76)$. Os valores obtidos são inferiores ao obtidos em estudos de arborização urbana realizados em outras regióes do país. Bortoleto et al. (2007) obteve um IDS de 3,90 para 161 espécies das ruas da Estância de Águas de Sáo Pedro /SP e em Assis/SP o valor do IDS foi de 2,91(ROSSATO et al, 2008). O baixo valor do IDS obtido nessas cidades pode estar relacionado ao número limitado de espécies usadas na arborização viária.

\section{Características dendrométricas dos indivíduos arbustivo-arbóreos}

Nas cidades de Alta Floresta (55,0\%), Carlinda (61,8\%) e Nova Monte Verde $(79,9 \%)$ dos indivíduos arbustivoarbóreos amostrados foram plantados em calçadas sem fiaçôes elétricas e telefônicas. Comumente, as calçadas sem fiação apresentam maior quantidade de indivíduos, em comparação com as calçadas com presença de fiação. Essa medida pode ser atribuída à tentativa de redução dos conflitos entre a arborização urbana e esse elemento urbano. Essa característica pode ser observada em outras localidades, como na cidade de Assis/SP (ROSSATO et al., 2008) e em Curitiba/PR (LEAL et al., 2008).

A classe de altura total $\left(\mathrm{h}_{\mathrm{t}}\right)$ II $\left(3<\mathrm{h}_{\mathrm{t}}<6 \mathrm{~m}\right)$ teve destaque quanto ao número de indivíduos amostrados nas cidades de Alta Floresta (52,2\%) e Carlinda (54,9\%). A distribuição da altura total das árvores em Nova Monte Verde é considerada adequada quando a arborização urbana é pensada no futuro, pois ocorreu a presença de indivíduos em todas as classes de altura (Figura 1-A). Nessa cidade o maior número de indivíduos concentra-se nas menores classes e vai decaindo nas classes de maior altura, caracterizando uma distribuição em "jota invertido", igualmente encontrado nas florestas tropicais (CORDEIRO e RODRIGUES, 2007). Entretanto, a elevada frequência de indivíduos com altura inferior a 3,0 m contraria a recomendação para não efetuar o plantio de indivíduos com altura total inferior a $2,50 \mathrm{~m}$, tendo em vista que essa é a fase crítica para pegamento das mudas e quanto mais desenvolvida estiverem, maiores são as chances de atingirem a vida adulta (SÃO PAULO, 2005; GONÇALVES e PAIVA, 2004). Outra questáo importante, que deve ser considerada é que os indivíduos de pequena estatura são mais suscetíveis aos atos de vandalismo.
Embora o número de indivíduos, com altura superior à $6,0 \mathrm{~m}$ tenha sido reduzido, há que se considerar que essas espécies poderáo atingir maiores alturas por se tratar de espécies de porte elevado como é Licania tomentosa, Ficus benjamina e Mangifera indica (LORENZI, 2006; LORENZI, 2008;). Essa constatação contraria os resultados obtidos na análise da arborização urbana em outras cidades brasileiras que enfrentam o processo de substituição da cobertura vegetal viária, das árvores de médio e grande porte, por espécies de pequeno porte e arbustos (ALVAREZ, 2004; BORTOLETO et al., 2007). Do ponto de vista ambiental, o elevado número de espécies de médio e grande porte utilizadas na arborização viária das cidades estudadas é interessante, pois, segundo Milano e Dalcin (20000), espécies de pequeno porte e arbustos, por suas características, apresentam possibilidades restritas de contribuição para melhoria climática e ambiental das cidades.

Quanto à altura da bifurcação $\left(h_{b}\right)$ das árvores utilizadas na arborização urbana, Nova Monte Verde $(88,1 \%)$, Alta Floresta $(88,4 \%)$ e Carlinda (97,8\%) dos indivíduos foram agrupados na classe $\mathrm{I}\left(\mathrm{h}_{\mathrm{b}}<1,8 \mathrm{~m}\right)$ (Figura 1-B). A alta concentração de indivíduos na primeira classe de altura de bifurcação do tronco, nas três cidades avaliadas está em total desacordo com as recomendaçóes técnicas, podendo indicar a baixa qualidade das mudas utilizadas nos plantios aleatórios e também a falta de condução adequada das mesmas após o plantio. SÃO PAULO (2005) recomenda que as mudas para plantio devem apresentar, preferencialmente, fuste com altura mínima de 1,8 m e quando apresentarem ramificaçóes laterais abaixo dessa altura, após o plantio, devem ser submetidas à poda de formação. É importante considerar a altura mínima da bifurcação das árvores, principalmente quando essas são plantadas nas calçadas, visando reduzir possíveis acidentes e dificultando o trânsito de pedestres.

Nas cidades de Carlinda (69,6\%) e Nova Monte Verde $(56,5 \%)$ dos indivíduos amostrados pertenciam à classe diamétrica I (DAS < 0,2 m), já em Alta Floresta, 60,6\% dos indivíduos se enquadraram na classe II $(0,2 \mathrm{~m}<$ DAS $<0,4 \mathrm{~m}$ ) (Figura 1-C). Licania tomentosa foi a espécie mais frequente nas três cidades, nas classes diamétricas I e II. O predomínio de indivíduos na classe diamétrica I nas cidades de Carlinda e Nova Monte Verde pode ser atribuída à jovialidade da arborização, uma vez que o processo de urbanização dessas cidades é recente. Carlinda e Nova Monte Verde foram emancipadas há 15 e 18 anos, respectivamente (MATO GROSSO, 2008). Os resultados obtidos em Alta Floresta indicam que se trata de uma população arbórea já estabelecida, ou seja, com maior participação de indivíduos adultos. Situação semelhante foi detectada em Santos/SP, onde apenas 33\% dos indivíduos apresentaram DAP menor que 0,2 m (MENEGHETTI, 2003). 
Essa situaçáo citada acima não é adequada. Uma possível reduçáo no plantio de novas mudas pode comprometer futuramente a arborizaçáo urbana, na cidade de Alta Floresta. Forman e Godran (1986) ressaltam a necessidade de um alto percentual de indivíduos jovens, devido à alta mortalidade neste período, para se ter um número razoável de indivíduos adultos.

Em Nova Monte Verde 55,2\% do total de indivíduos foram agrupados na classe de diâmetro de copa I. Já nas cidades de Carlinda (52,9) e Alta Floresta $(67,7 \%)$ dos indivíduos amostrados pertenceram à classe II (Figura 1-D). O diâmetro de copa é uma variável importante quando se discute os benefícios da arborizaçáo urbana e quanto maior e mais densa for a copa maior o poder de sombreamento (MILANO, 1988). Do ponto de vista ambiental, Licania tomentosa, que foi a espécie mais frequente nas três cidades, apresenta resultados satisfatórios quanto ao sombreamento, pelas características da copa (LORENZI, 2008).

\section{Adequação da arborização viária em relação ao espaço disponível}

Segundo Pivetta e Silva Filho (2004), as ruas com larguras superiores a 7,00 $\mathrm{m}$ são consideradas largas e com base nessa classificação, todas as ruas amostradas em Carlinda e Nova Monte Verde são largas, enquanto Alta Floresta, foram amostradas ruas estreitas (largura $<7,0 \mathrm{~m}$ ) e ruas largas. Uma característica comum entre as três cidades é a ocorrência de recuos largos, devido ao afastamento dos lotes. Segundo Paiva e Gonçalves (2002), essa disponibilidade de espaço permite o plantio de espécies de médio e grande porte.

De acordo com a Tabela 03, em todas as cidades a distância média entre o local de plantio das espécies e o alinhamento da fiação é superior a um metro. Entretanto, com base nas distâncias mínimas, possivelmente, em alguns pontos as árvores estejam exatamente sob a fiação. Conforme os dados médios, nas cidades estudadas, ainda não há intensa concorrência direta das copas com a fiação elétrica de baixa e alta tensão, haja vista que a altura média dos indivíduos nas proximidades da rede elétrica, em todas as cidades é inferior a 6,0 m. No entanto, ao considerar que as espécies mais frequentes nas três cidades podem atingir altura superior a 10 $\mathrm{m}$, é possível afirmar que os órgãos competentes e os próprios moradores devem necessitar de tempo e dinheiro para manter essas árvores.

O plantio de árvores de grande porte sob a rede elétrica é possível, desde que a muda náo seja plantada no alinhamento da rede e que a copa das árvores seja conduzida precocemente, através do trato cultural adequado, acima dessa rede (SÃO PAULO, 2005). Entretanto, haverá conflito enquanto a

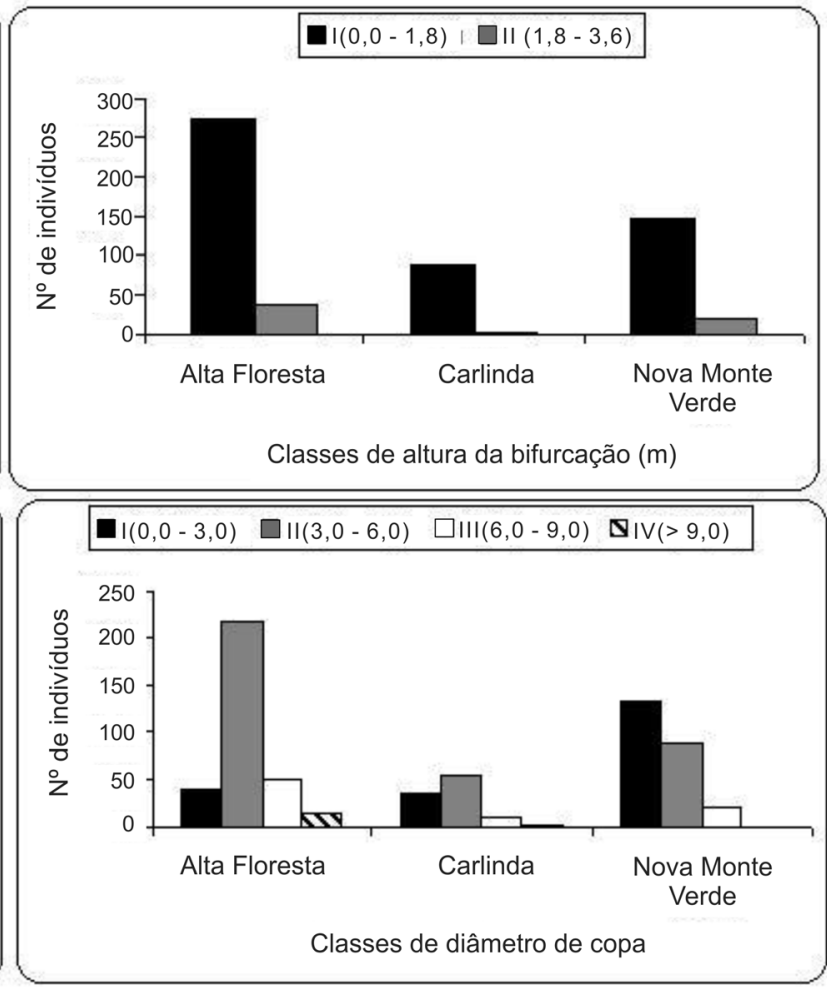

Figura 01 - Características das espécies arbóreas ocorrentes na arborização urbana de três cidades da região norte de Mato Grosso; 1-A - distribuição da altura total $(\mathrm{m})$ dos indivíduos; 1-B - distribuição da altura da bifurcação $(\mathrm{m})$; 1-C - distribuiç̧ão do diâmetro $(\mathrm{m})$ à $0,5 \mathrm{~m}$ do solo (DAS); 1-D - distribuição do diâmetro de copa $(\mathrm{m})$ dos indivíduos. 
árvore estiver em formação (VELASCO et al., 2006). É importante considerar, nessa situaçáo, a adequação do sistema de distribuição de energia, de forma a reduzir os conflitos e consideravelmente os gastos preventivos e corretivos para manutenção da rede elétrica e da arborizaçáo conjuntas (BRITO e CASTRO, 2007).

Conforme a Tabela 03, nas três cidades avaliadas, as árvores são plantadas próximas aos muros e, em decorrência de recuos largos, o grau de sombreamento das vias é baixo. A distância média das árvores ao meio-fio nas três cidades estudadas está bem acima da recomendação técnica de Milano (1988) que é $1 \mathrm{~m}$ de distância do meio fio. O sombreamento beneficiaria os pedestres que se deslocam com mais conforto sob a sombra das árvores e também os automóveis que estejam estacionados no acostamento dessas vias ou mesmo transitando pelo local através da redução da temperatura interna e, consequentemente, menor consumo de energia para o resfriamento de seu interior, se for o caso. Quando são plantadas muito próximas aos muros, as árvores podem acarretar danos como o levantamento e rachadura da alvenaria provocados pelas raízes (SILVA FILHO et al., 2002), sombreamento excessivo no jardim residencial (GONÇALVES e PAIVA, 2004) e os galhos das árvores, podem facilitar a entrada de ladróes através do muro (MONICO, 2001).

A estimativa da distância média entre árvores obteve os seguintes valores médios em cada cidade estudada: Carlinda (17,8 m), Nova Monte Verde (18,0 m) e Alta Floresta (20,1 m). Os resultados obtidos apontam um número razoável de árvores plantadas nas ruas das cidades avaliadas, no entanto, encontramse acima da recomendação técnica. De acordo com São Paulo (2005) as árvores de porte médio e grande devem ser plantadas em espaçamentos mínimos de 8,0 a 12,0 m, respectivamente. Milano (1988) considera uma árvore a cada $12 \mathrm{~m}$ como um índice adequado para se obter uma boa arborização.

A densidade de árvores/ $\mathrm{km}$ de calçada estimado nas cidades avaliadas obteve os seguintes valores: Alta Floresta - 47,7 árvores $/ \mathrm{km}$, Nova Monte Verde - 52,3 árvores $/ \mathrm{km}$ e Carlinda - 56,0 árvores $/ \mathrm{km}$. Esse valores se encontram acima da densidade estimada por Rachid e Couto (1999) na cidade de São Carlos/SP, estimou 30,1 árvores/km de calçada, no entanto, em Águas de Sáo Pedro Bortoleto et al. (2007) obtiveram 130 árvores $/ \mathrm{km}$. A alta densidade de árvores nas calçadas das cidades avaliadas não caracteriza que a arborização viária esteja bem planejada. Para PAIVA e GONÇALVES (2002) há que se considerar, entre outros fatores, a dimensão e a qualidade da copa da árvore, além da situação da própria árvore, ou seja, a cobertura arbórea do local.

Foram encontradas árvores plantadas próximas aos elementos urbanos nas três cidades estudadas, no que se refere à distância da árvore ao poste, esquina e placas de sinalização de trânsito. Porém, o número de árvores, nessa situação, apresentou baixa representatividade em relação ao número total de indivíduos amostrados.

\section{CONCLUSÃO}

A arborização viária, nas três cidades estudadas apresenta número reduzido de espécies, aliado à frequência irregular das mesmas, nas vias amostradas, sendo que a cidade de Carlinda apresentou as espécies distribuídas de maneira mais crítica, em comparaçấo com as outras duas cidades.

Além da distribuição irregular das espécies, algumas falhas detectadas na arborização das cidades estudadas, tais como a altura da bifurcação inferior a $1,80 \mathrm{~m}$ na maior parte dos indivíduos, plantio realizado próximo aos muros e indivíduos de estatura muito pequena, podem comprometer a qualidade da arborização viária.

Licania tomentosa foi a espécie mais frequente nas cinco cidades, mostrando-se adaptada aos ambientes urbanos da regiáo, no entanto, a frequência de plantio excessivamente alta não é recomendada. Todas as cidades avaliadas devem procurar a introdução de novas espécies arbustivas e arbóreas nativas da região na arborização viária, haja vista que o uso de espécies exóticas foi predominante.

Podem ocorrer conflitos entre as árvores das redes viárias com a fiação elétrica e telefônica, devido o uso de espécies de porte elevado sob a fiação, sem planejamento.

Tabela 03 - Dimensionamento das redes viárias e recuos, altura das árvores e fiações e distanciamento dos componentes urbanos em relação ao meio-fio nas cidades de Alta Floresta, Carlinda e Nova Monte Verde situadas na região norte do Estado de Mato Grosso.

\begin{tabular}{lccccccc}
\hline Cidade & $\begin{array}{c}\text { Largura da via } \\
(\mathrm{m})\end{array}$ & $\begin{array}{c}\text { Largura do recuo } \\
(\mathrm{m})\end{array}$ & DPMF & DAMF & Altura da árvore $(\mathrm{m})$ & AFBT & AFAT \\
\hline & méd:6,9 & méd: 5,4 & méd: 2,3 & méd: 3,8 & méd: 5,9 & méd: 6,9 & méd: 9,0 \\
Alta Floresta & Mín: 6,3 & Mín: 4,1 & Mín: 1,8 & Mín: 1,2 & Mín: 1,6 & Mín: 6,5 & Mín: 8,5 \\
& Máx: 7,5 & Máx: 6,3 & Máx: 3,2 & Máx: 5,8 & Máx: 13,0 & Máx: 7,5 & Máx: 9,5 \\
\hline Carlinda & méd: 8,3 & méd: 4,5 & méd: 2,1 & méd: 3,4 & méd: 4,4 & méd: 7,3 & méd: 9,0 \\
\hline
\end{tabular}


Por conta de deficiências no planejamento da arborização urbana das cidades estudadas as árvores foram plantadas distante do meio-fio, consequentemente o grau de sombreamento das vias e calçadas é reduzido.

\section{BIBLIOGRAFIA CITADA}

ALVAREZ, I.A. Qualidade do espaço verde urbano: uma proposta de índice de avaliação. 2004. 187 f. Tese (Doutorado em Agronomia) - Universidade de São Paulo, Piracicaba-SP.

BORTOLETO, S.; SILVA FILHO, D. F.; SOUZA, V. C.; FERREIRA, M. A. P.; POLIZEL, J. L.; RIBEIRO, R. C. S. Composição e distribuição da arborização viária da estância de Águas de São Pedro-SP. Revista da Sociedade Brasileira de Arborização Urbana, Piracicaba, v. 2, n. 3, set., p. 32-46, 2007.

BRITO, M. L. S.; CASTRO, P. M. Viabilidade econômica de redes de distribuição protegidas. Revista da Sociedade Brasileira de Arborização Urbana, Piracicaba, v. 2, n. 1, mar., p. 130-137, 2007.

CARVALHO, P. E. R. Espécies arbóreas brasileiras. 1. ed. Brasília: Embrapa Informação Tecnológica, 2003, v. 1, 1039 p.

CARVALHO, P. E. R. Espécies arbóreas brasileiras. 1. ed. Brasília: Embrapa Informação Tecnológica, 2006, v. 2, 627 p.

CARVALHO, P. E. R. Espécies arbóreas brasileiras. 1. ed. Brasília: Embrapa Informação Tecnológica, 2008, v. 3, 593 p.

CORDEIRO, J.; RODRIGUES, W. A. Caracterização fitossociológica de um remanescente de floresta ombrófila mista em Guarapuava, PR. Árvore, Viçosa, v. 31, n. 3, p. 545-554, 2007.

FORMAN, R. T. T.; GODRON, M. Landscape ecology. New York: John Wiley, 1986. $620 \mathrm{p}$

GONÇALVES, W.; PAIVA, H. N. Árvores para o ambiente urbano. Viçosa: Aprenda Fácil, 2004. 242 p. (Coleção Jardinagem e Paisagismo, 3).

LEAL, L; BIONDI, D.; ROCHADELLI, R. Custos de implantação e manutenção da arborização de ruas da cidade de Curitiba, PR. Árvore, Viçosa, v. 32, n. 3, mai./jun., p. 557-565, 2008.

LORENZI, H. Árvores Brasileiras: manual de identificação e cultivo de plantas arbóreas nativas do Brasil. 2. ed. Nova Odessa: Instituto Plantarum, 2002, v. 2, 382 p.

LORENZI, H. Árvores Brasileiras: manual de identificação e cultivo de plantas arbóreas nativas do Brasil. 5. ed. Nova Odessa: Instituto Plantarum, 2008, v. 1, 368 p.

LORENZI, H. et al. Árvores Exóticas no Brasil: madeireiras, ornamentais e aromáticas. 1 ed. Nova Odessa: Instituto Plantarum, 2003. 384 p.

LORENZI, H. et al. Frutas brasileiras e exóticas cultivadas: (de consumo in natura). Nova Odessa: Instituto Plantarum, 2006. $640 \mathrm{p}$.

MASCARÓ, L. E. A. R.; MASCARÓ, J. L. Vegetação urbana. 2. ed. Porto Alegre: Mais Quatro Editora, 2005. 204 p.

MATO GROSSO. Informativo socioeconômico de Mato Grosso: 2005. Cuiabá: Central de Texto, 2005.
MATO GROSSO. Secretaria de Estado de Planejamento. Anuário estatístico de Mato Grosso de 2007. Cuiabá: Carlini e Caniato Editorial, 2008. 762 p.

McPHERSON, E. G. A benefit-cost analysis of ten street tree species in Modesto, California, U. S. Journal of Arboriculture, Champaign, v. 29, n.1, jan, p.1-7, 2003.

MELO, R. R.; LIRA FILHO, J. A.; RODOLFO JÚNIOR, F. Diagnóstico qualitativo e quantitativo da arborização urbana no bairro Bivar Olinto, Patos, Paraíba. Revista da Sociedade Brasileira de Arborização Urbana, v. 2, n. 1, mar., p.64-78, 2007.

MENEGHETTI, G.I.P. Estudo de dois métodos de amostragem para inventário da arborizaçáo de ruas dos bairros da orla marítima do município de Santos-SP. 2003. 100 f. Dissertação (Mestrado em Recursos Florestais) - Universidade de São Paulo, Piracicaba-SP.

MILANO, M. S. Avaliação e análise da arborização de ruas de Curitiba-PR. 1984. 130 f. Dissertação (Mestrado em Ciências Florestais) - Universidade Federal do Paraná, Curitiba-PR.

MILANO, M. S. Avaliação quali-quantitativa e manejo da arborização urbana: exemplo de Maringá - PR. 1988. 120 f. Tese (Doutorado em Ciências Florestais) - Universidade Federal do Paraná, Cutitiba-PR.

MILANO, M. S.; DALCIN, E. C. Arborização de vias públicas. Rio de Janeiro: Light, 2000. 226 p.

MONICO, I. M. Árvores e arborização urbana na cidade de Piracicaba/SP: um olhar sobre a questão à luz da educação ambiental. 2001. 165 f. Dissertação (Mestrado em Recursos Florestais) - Universidade de São Paulo, Piracicaba-SP.

PAIVA, H. N.; GONÇALVES, W. Florestas urbanas: planejamento para melhoria da qualidade de vida. Viçosa: Aprenda Fácil, 2002. 180 p. (Coleção Jardinagem e Paisagismo, 2).

PIVETTA, K. F. L.; SILVA FILHO, D. F. Boletim acadêmico: Série arborização urbana. Jaboticabal: FUNEP, 2002. 68 p.

RACHID, C.; COUTO, H. T. Z. Estudo da eficiência de dois métodos de amostragem de árvores de rua na cidade de São Carlos - SP. Scientia Forestalis, Piracicaba, n. 56, p. 59-68, 1999.

ROSSATTO, D. R.; TSUBOY, M. S. F.; FREI, F. Arborização urbana na cidade de Assis-SP: uma abordagem quantitativa. Revista da Sociedade Brasileira de Arborização Urbana, Piracicaba, v. 3, n. 3, set., p. 1-16, 2008.

SANTANA, J. R. F.; SANTOS, G. M. M. Arborização do campus da UEFS: exemplo a ser seguido ou um grande equívoco? Sitientibus, Feira de Santana, n. 20, jan/jun, p.103-107, 1999.

SÃO PAULO. Secretaria Municipal do Verde e do Meio Ambiente. Manual técnico de arborização urbana. 2. ed. São Paulo: Nacional, 2005. 45p.

SHANLEY, P.; MEDINA, G. (Eds.) Frutiferas e plantas úteis na vida amazônica. Belém: CIFOR, 2005. 296 p.

SILVA FILHO, D. F; BORTOLETO, S. Uso de indicadores de diversidade na definiçáo de plano de manejo da arborizaçáo viária de águas de São Pedro - SP. Árvore, Viçosa, v. 29, n. 6, p. 973-982, 2005.

SILVA FILHO, D. F.; PIZETTA, P. U. C.; ALMEIDA, J. B. S. A.; PIVETTA, K. F. L.; FERRAUDO, A. S. Banco de dados 


\section{ACTA}

relacional para cadastro, avaliação e manejo da arborização em vias públicas. Árvore, Viçosa, v. 26, n. 5, p. 629-642, 2002.

SILVA, L. F.; VOLPE-FILIK, A.; LIMA, A. M. L. P.; SILVA FILHO, D. F. Participação comunitária no planejamento viário de alguns bairros da cidade de Americana/SP. Revista da Sociedade Brasileira de Arborização Urbana, Piracicaba, v. 2, n. 3, set., p. 47-63, 2007.

VELASCO, G. D. N.; LIMA, A. M. L.; COUTO, H. T. Z. Análise comparativa dos custos de diferentes redes de distribuição de energia elétrica no contexto da arborização urbana. Árvore, Viçosa, v. 30, n. 4, p. 679-686, 2006.
WESTPHAL, L. N. Urban greening and social benefits: a study of empowerment outcomes. Journal of Arboriculture, Champaign, v. 29, n. 3, may, p. 137-147, 2003.

Recebido em 03/05/2009

Aceito em 25/01/2010 
